\title{
Balloons and stents in the endovascular treatment of cerebral aneurysms: vascular anatomy remodeled
}

\section{Michel Piotin* and Raphaël Blanc}

Department of Interventional Neuroradiology, Foundation Rothschild Hospital, Paris, France

\section{Edited by:}

Italo Linfante, Baptist Cardiac and

Vascular Institute, USA

\section{Reviewed by:}

Angelos A. Konstas, Massachusetts General Hospital, USA

Italo Linfante, Baptist Cardiac and

Vascular Institute, USA

\section{*Correspondence:}

Michel Piotin, Department of

Interventional Neuroradiology,

Foundation Rothschild Hospital, 25

Rue Manin, 75019 Paris, France

e-mail:michel.piotin@me.com
Wide-neck intracranial aneurysms were originally thought to be either untreatable or very challenging to treat by endovascular means because of the risk of coil protrusion into the parent vessel. The introduction of the balloon remodeling technique (BRT) and later stents specifically designed for intracranial use has progressively allowed these lesions to be endovascularly treated. BRT and stent-assisted coiling technique (SACT) were first designed to treat sidewall aneurysms but, with gained experience and further technical refinement, bifurcation complex-shaped wide-neck aneurysms have been treated by coiling enhanced by BRT and SACT. In this article, we will review and describe the inherent benefits and drawbacks of BRT as well as SACT.

Keywords: aneurysm, coiling, balloon remodeling, stent-assisted coil embolization, complications, strategies, angiography, vascular diseases

\section{INTRODUCTION}

Wide-neck (when the neck is $\geq 4 \mathrm{~mm}$, or when the dome/neck ratio $<1.5-2$ ) intracranial aneurysms were originally thought to be either untreatable or very challenging to treat by endovascular means because of the risk of coil protrusion into the parent vessel. The introduction of the balloon remodeling technique (BRT) and later stents specifically designed for intracranial use has progressively allowed these lesions to be endovascularly treated. BRT and stent-assisted coiling technique (SACT) were first designed to treat sidewall aneurysms but, with gained experience and further technical refinement, bifurcation complex-shaped wide-neck aneurysms have been treated by coiling enhanced by BRT and SACT. In this article, we will review and describe the inherent benefits and drawbacks of BRT as well as SACT. The specific role of flow diverter stents in the endovascular treatment of cerebral aneurysms will not be addressed in this article.

\section{BALLOON REMODELING TECHNIQUE VARIOUS TECHNIQUES OF BALLOON REMODELING}

The standard coil embolization (stand-alone coiling) technique is limited by its inability to occlude wide-neck aneurysms. The BRT consists in the temporary inflation of a non-detachable balloon across the aneurysm neck during each coil placement to avoid inadvertent coil protrusion into the parent artery as initially described by Moret et al. nearly two decades ago (1). At the end of the procedure, the balloon is removed and no device is left in place in the parent vessel (unless stent placement is subsequently performed). Some balloon catheters allow the placement of a stent at the end of the procedure by inserting the stent into the lumen of the balloon microcatheter after withdrawal of the wire (2). The "classic" BRT, using a single low-compliance balloon, was initially limited to sidewall aneurysms, and was often inadequate for protection of both the neck and arterial branches of complex bifurcation aneurysms. Nowadays, the most popular remodeling balloon microcatheters are the HyperGlide ${ }^{\mathrm{TM}}$ (compatible with $0.010^{\prime \prime}$ microguidewire), the Transform ${ }^{\mathrm{TM}}$, and the Septer ${ }^{\mathrm{TM}}$ (both compatible with $0.014^{\prime \prime}$ microguidewires). Balloons compatible with $0.014^{\prime \prime}$ microwire seem more stable than balloon operating on $0.010^{\prime \prime}$ platforms but induce more deformation of the cerebral arteries during navigation. The Septer ${ }^{\mathrm{TM}}$ has two independent lumens, giving to the operator the opportunity to navigate coils or some microstents while the balloon is still inflated. For bifurcated lesions, the use of more compliant balloon (compliance is a mechanical property defined by the propensity of the balloon to change its cylindrical shape to the anatomy of the vessel in which it is inflated) allows the treatment of complex, wide-neck bifurcation aneurysms for which the standard embolization technique would not have permitted safe (regarding the patency of bifurcation arterial branches) endovascular occlusion. In these situations, it is necessary to completely protect the neck to avoid coil protrusion. Several options are available. First, a more compliant balloon can be used to mold the neck and the origin of bifurcation branches (3). The most popular compliant balloons microcatheters are the HyperForm $^{\mathrm{TM}}$ (compatible with $0^{\prime \prime}$ microguidewire), the Transform ${ }^{\mathrm{TM}} \mathrm{C}$ and SC (C and SC for compliant and super compliant, respectively) and the Septer $\mathrm{C}$ and $\mathrm{SC}^{\mathrm{TM}}$ (both compatible with 0.014 microguidewires). An alternative to the use of a super compliant balloon consists in the placement of two balloons instead of one (one balloon in each of the bifurcated arterial branches) (4). The third option consists in the navigation of the balloon through the circle of Willis to cross and protect the aneurysm neck (e.g., to navigate from the internal carotid, the posterior communicating arteries and the $\mathrm{P} 1$ segment of both posterior cerebral arteries to protect the neck of a basilar tip aneurysm) (5). Another technique consists in the navigation of a dual-lumen balloon in front of the neck to allow coil deposition through the second lumen of the balloon microcatheter (6). Nowadays, BRT can be used in all aneurysm locations. 


\section{COMPLICATIONS AND CLINICAL OUTCOME OF BRT}

The two most frequent and feared complications of the endovascular treatment of intracranial aneurysms are thromboembolic events and aneurysm perforation. The use of an adjunctive balloon for aneurysm coiling has raised some concerns about potential added morbidity over the standard coiling procedure. In a recent large prospective multicenter study, a consecutive series of patients with ruptured aneurysms (the CLARITY study) who underwent endovascular treatment with either conventional coil embolization or BRT showed that both techniques had similar safety in terms of perioperative complications and clinical outcome (7). The overall rate of treatment-related complications, with or without clinical manifestations, was $17.4 \%$ with coil embolization and $16.9 \%$ with BRT. The difference in the rates of thromboembolic events, intraoperative rupture, and early rebleeding between the two treatment groups was not statistically significant. The cumulative morbidity and mortality rate related to the treatment in the remodeling group $(3.8 \%)$ was similar to that in the stand-alone coil embolization group (5.1\%). Likewise, the global cumulative morbidity and mortality rates related to both the treatment and the initial hemorrhage did not differ significantly between groups (16.2\% with BRT and $19.6 \%$ with coil embolization). In the ATENA study (unruptured aneurysms) (8), the overall complication rate, regardless of whether the adverse events led to clinical consequences, was $10.8 \%$ for standard coiling of unruptured aneurysms and $11.7 \%$ for BRT of unruptured aneurysms. The morbidity and mortality rates did not differ significantly between groups: $3.1 \%$ in the standard treatment group and $3.7 \%$ in the BRT group, respectively (8). In the Shapiro et al. review article (9), in ruptured aneurysms, the clinical outcome was a symptomatic event or death in $2.7 \%$ in the standalone coiling group and $1.7 \%$ in the BRT group. In unruptured aneurysms, clinical outcome was a symptomatic event or death in $0.6 \%$ in the stand-alone coiling group and $0.9 \%$ in the BRT group. Table 1 provides with an overview of the rates of complications with BAT.

\section{ANEURYSM PERFORATION}

In the Shapiro et al. review article (9), the rate of intraoperative rupture was $3.4 \%$ in ruptured aneurysms treated with standard coiling, $1.7 \%$ in ruptured aneurysms treated with the remodeling technique, $1.4 \%$ in unruptured aneurysms treated with standard coiling, and $1.8 \%$ in unruptured aneurysms treated with the remodeling technique. In the ATENA study (unruptured aneurysms) (8), the rate of intraoperative rupture was $3.2 \%$ in the

Table 1 | Balloon remodeling technique and complications with clinical significance.

\begin{tabular}{lcc}
\hline & \multicolumn{2}{c}{ Morbi-mortality } \\
\cline { 2 - 3 } & $\begin{array}{l}\text { Stand-alone } \\
\text { coiling (\%) }\end{array}$ & $\begin{array}{c}\text { BRT } \\
\text { (\%) }\end{array}$ \\
\hline CLARITY, ruptured aneurysms (7) & 5.1 & 3.8 \\
ATENA, unruptured aneurysms (8) & 3.1 & 3.7 \\
Shapiro et al. review, ruptured aneurysms (9) & 2.7 & 1.7 \\
Shapiro et al. review, unruptured aneurysms (9) & 0.6 & 0.9
\end{tabular}

remodeling group and $2.2 \%$ in the coiling group. In the Sluzewski et al. personal series (10), the rate of intraoperative rupture was higher in the remodeling (4.0\%) compared with the coiling group $(0.8 \%)$. In the CLARITY study (ruptured aneurysms), the rates of intraoperative rupture were similar in both BRT and stand-alone coiling groups (7).

\section{THROMBOEMBOLIC COMPLICATIONS}

In the Shapiro et al. review (9), the rate of thromboembolic events was similar in patients treated with coiling $(8.1 \%)$ and remodeling $(8.0 \%)$. Symptomatic thromboembolic events were encountered in $4.6 \%$ of patients treated with coiling and $4.4 \%$ of patients treated with remodeling. Death related to thromboembolic events was reported as $1.2 \%$ for patients treated with coiling and $0.4 \%$ for patients treated with remodeling. In the Layton et al. series (11), the rate of thrombus formation was not significantly different in patients treated with standard coiling compared with the remodeling technique ( 9 and $14 \%$, respectively). Symptomatic thromboembolic events were also observed in a similar percentage of cases (5\% in standard coiling and 7\% in remodeling). Similarly, Brooks et al. reported that diffusion-weighted-imaging abnormalities were detected in $32 \%$ in the coiling group and $24 \%$ in the BRT (12). Conversely, Sluzewski et al. reported that the rate of thromboembolic events was higher in the remodeling group $(9.8 \%)$ compared with the coiling group $(2.2 \%)(10)$. In the ATENA study, thromboembolic events occurred in $6.2 \%$ in the stand-alone coiling group versus $5.4 \%$ in the BRT group (8).

\section{ROLE OF BALLOON INFLATION TIME FOR BRT REGARDING ISCHEMIC COMPLICATIONS}

Critical questions regarding the maximum permissible balloon occlusion time, the minimum effective reperfusion time between inflations, and whether total balloon inflation time or the number of inflations is a higher risk factor of BRT than stand-alone coiling for ischemic complications has been assessed using diffusionweighted MR imaging $(13,14)$. For Albayram et al., the only variables found to influence this risk during or after BRT coil placement were microcatheter repositioning, coil removal and repositioning, and size of the aneurysmal neck (13). More recently, Spiotta et al. found that asymptomatic ischemic event rate in this population for BRT embolization was $24.7 \%$, a rate equal to standalone coiling of patients treated in the same time period without BRT (14). Both silent and symptomatic ischemic rates were similar in the internal control group. It is possible that the higher rate of antiplatelet therapy in the BRT group is masking a higher ischemic rate. The baseline patient risk factors for ischemic complications identified included older age and diabetes. One possible explanation for this finding is that all patients have intraprocedural showering of emboli, but older and diabetic patients are more likely to have irreversible ischemia attributable to preexisting microvascular disease. Embolic infarcts were more common than watershed infarcts. The total number of inflations times, the maximum occlusion time, minimum reperfusion time between two consecutive inflations, and mean reperfusion time did not appear to be risk factors for thromboemboli. However, higher maximum inflation time was significantly correlated to watershed pattern infarcts. 


\section{ANATOMIC RESULTS OF THE BRT}

The Shapiro et al. literature review does not confirm the Sluzewski et al. findings $(9,10)$. Both initial and follow-up aneurysm occlusion rates were higher in BRT cases. The initial total occlusion rate was $73 \%$ in patients in the BRT group and $49 \%$ of patients in the standard coiling group, subtotal occlusion in $22 \%$ in the BRT group and 39\% in the coiling group, and incomplete occlusion in $5 \%$ in the BRT group and $13 \%$ in the coiling group. At follow-up, there were similar results: total occlusion in $72 \%$ of patients in the BRT group and $54 \%$ of patients in the standard coiling group, subtotal occlusion in $17 \%$ in the BRT group and $34 \%$ in the coiling group, and incomplete occlusion in $10 \%$ of the BRT group and $11 \%$ of the coiling group. According to the ATENA and CLARITY studies, results are possibly different in unruptured and ruptured aneurysms. In ATENA (unruptured aneurysms), immediate anatomic results reported were similar in both stand-alone coiling and BRT groups (complete occlusion in 59.8\% of aneurysms in the stand-alone coiling group and $59.8 \%$ of aneurysms in the BRT group) (8). In CLARITY (ruptured aneurysms) (7), immediate anatomic results were different, the rate of adequate angiographic aneurysm occlusion being significantly higher in the BRT group (94.9\%) than in the stand-alone coil embolization group $(88.7 \%)$. A recent meta-analysis from Shapiro et al. demonstrated that although balloon use was associated with superior initial and follow-up angiographic occlusion rates (9).

\section{STENT-ASSISTED COILING OF INTRACRANIAL ANEURYSMS RATIONALE FOR THE STENTING OF INTRACRANIAL ANEURYSMS}

The widespread acceptance of coiling has been hindered by the potential for aneurysm to recur over time after coiling (15). This issue is even more relevant for large aneurysms for which angiographic recurrence is more likely than smaller lesions (16). However, fusiform and some wide-neck aneurysms remained unaddressed by both reconstructive surgical and endovascular techniques until the introduction of dedicated intracranial selfexpandable stent. Stent deployment across the aneurysm neck, followed by coil packing of the aneurysm, has progressively been more widely adopted, particularly for wide-neck complex aneurysms, in order to stabilize the coil mass inside the aneurysmal sac and to avoid coil herniation into the parent artery (17, 18). Some authors have also advocated using the stent (or several stents deposited in a telescopic fashion to augment mesh density) as a stand-alone procedure to treat fusiform aneurysms, obtaining progressive aneurysm thrombosis without the adjunct of coils within the aneurysm sac (19-23). With gained experience, SACT has been employed to treat a larger range of aneurysms (not only wide-neck and complex aneurysms) with the idea of the likelihood of diminished risk of aneurysm recurrence (24-26). The major current concern is the small size of the parent vessel relative to the diameter of the smallest available stent with inherent potential suboptimal stent deployment. Nevertheless, some stents can be adequately deployed even in vessel smaller than $2 \mathrm{~mm}$ (27). Conversely, the use of SACT has brought with it other important considerations, including the necessity of antiplatelet therapy that carries inherent risks of intracranial bleeding $(28,29)$. Moreover, antiplatelet therapy is limited in the setting of subarachnoid hemorrhage for the majority of the operators (30). The other drawback, even if limited, of SACT is the potential for delayed stent-related issues such as the development of in-stent stenosis and parent vessel occlusion (31-33).

\section{CLOSE- AND OPEN-CELL DESIGNS FOR SELF-EXPANDABLE STENT}

There are two major different, close- and open-cell designs for the construction of self-expanding stents dedicated to the intracranial use. The close-cell design makes the stent to work as a whole body (e.g., Enterprise $\left.{ }^{\mathrm{TM}}\right)$; thus, a force used at one end will be transmitted to the other end immediately. For a stent with open-cell design (e.g., Neuroform ${ }^{\mathrm{TM}}$ ), each independent segment can serve as a separate fixing device, to enhance apposition of the stent to the arterial wall, and a force used at one end will not be transmitted to the other end so easily. Open-cell design stents better cover the aneurysm neck when compared to close-cell stents, and induce less straightening of the vessel. The open-cell stents have, however, less struts apposing well to the vessel wall compared to close-cell stents (34). Open-cell stents conforms better to vascular tortuosities. However, open-cell stents may show increased opening of cells and outward prolapse of struts into an aneurysm neck when situated at the convexity of the curvature, whereas at the concavity, struts, or stent segments may protrude inward.

When a closed-cell stent is bent, it has less flexibility to conform to a curved or irregular anatomy. The close-cell unsegmented design does not allow the stent to lengthen at the outer curve or to shorten at the inner curve. This limitation in adapting to a vessel curvature will cause flattening of the stent or kinking (35) resulting in incomplete stent apposition. Incomplete stent apposition has recently been found to be a critical factor associated with higher thromboembolic complication rates in SACT embolization of intracranial aneurysms (36). The major advantage of a closecell stent is ability to be deployed in the vessel lumen and resheated in its delivery microcatheter, allowing the operator to optimize the position of the stent regarding the aneurysm neck. Conversely, an open-cell stent, once partially delivered, cannot be resheated and repositioned owing to its design consisting in independent stent segments soldered by connectors.

There are two different types of close-cell stents: laser-cut (as the Enterprise ${ }^{\mathrm{TM}}$ ) or woven (as the LVIS ${ }^{\mathrm{TM}}$ and the $\mathrm{LEO}^{\mathrm{TM}}$ ). Nowadays, the last two stents offer the lowest profile to be delivered in a $0.017^{\prime \prime}$ inner lumen microcatheter.

\section{STENTING TECHNIQUES}

Four options may be proposed. Firstly, the coil delivery microcatheter can be placed first within the aneurysm lumen to allow coil delivery and then the stent is positioned and immediately delivered across the aneurysm neck (jailed-catheter technique). Secondly, the stent can be first delivered across the aneurysm neck and then the coiling microcatheter is placed within the sac through the stent struts (trans-cell technique) (Figure 1) (37). Finally, the aneurysm can be coiled with or without the balloon remodeling technique and then the stent is delivered across the aneurysm neck at the end of the procedure, aiming at decreasing the recanalization rate by diminishing intra-aneurismal flow by diversion and also by creating a mesh at the level of the neck to be colonized and covered by endothelial cells (25). On the other hand, delivering the stent prior to aneurysm coiling has some drawbacks. Firstly, 

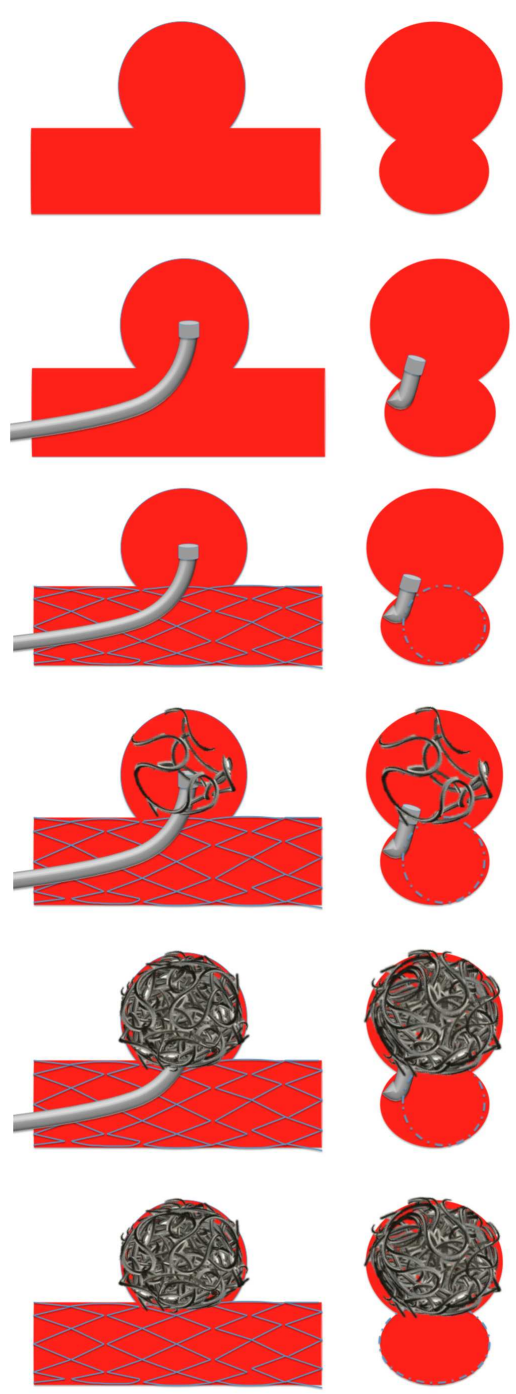

Jailed
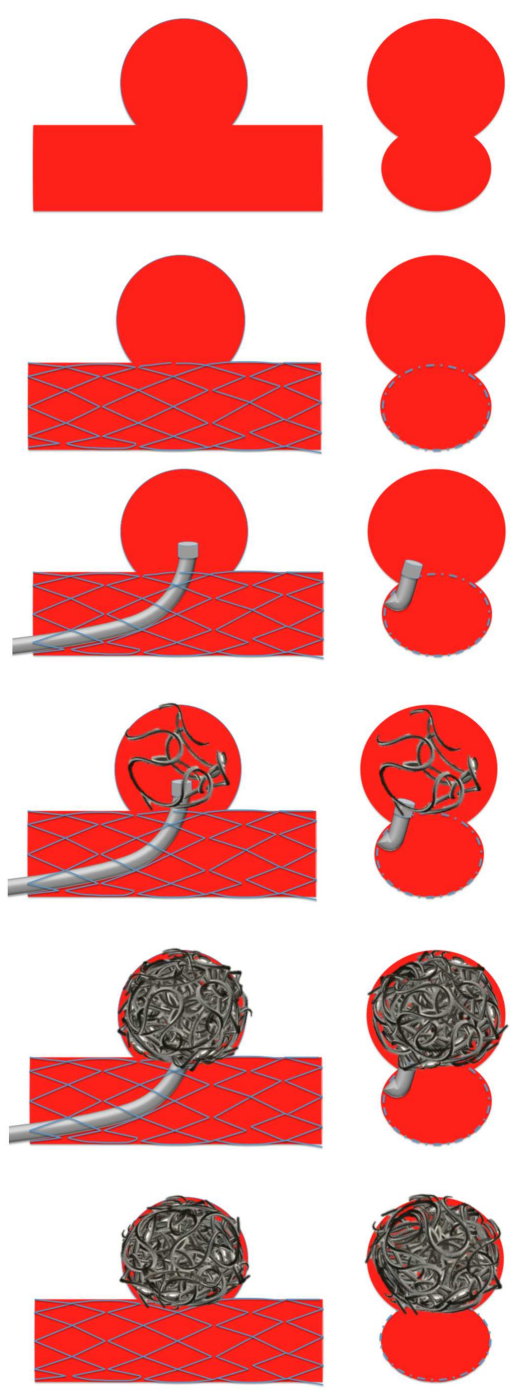

Trans-cell

FIGURE 1 | Jailed-catheter and trans-cell techniques.

the jailed-catheter technique does not offer the possibility to modify the microcatheter position within the aneurysm sac, resulting in many instances in the diminution of aneurysm packing with coils. Secondly, when the stent is deployed prior to the coil delivery microcatheter placement, the operator should be very cautious while catheterizing the aneurysm through the stent strut in keeping with the potential hazard of stent displacement and stent cell impingement (38). A fourth SACT, the stent-jack technique, has been more recently described. It consists in positioning the coil delivery microcatheter first into the aneurysm sac, then navigating a self-expandable stent into the parent vessel without delivering the stent before the first coil is deposited in the sac (39). The first coil is placed into the sac (no matter if a coil loop was slightly protruding into the arterial lumen) with coil deployment aiming at forming the most homogenous framing of the aneurysm sac. As a next step, before coil detachment, the stent is carefully deployed across the neck. Once the stent is delivered, the first coil is detached. If necessary, additional coils are introduced into the aneurysm to obtain circulatory exclusion of the lesion.

\section{STENTING OF BIFURCATION ANEURYSMS}

Stents have been designed originally to treat sidewall aneurysms. Single-stent SACT is suitable for many bifurcation aneurysms, as a stand-alone technique or in conjunction with BRT (the balloon to be placed in one of the bifurcated branch, the stent being delivered in the other branch). More recently, double stenting in a Y or X configuration may be used to treat a subset of wide-necked aneurysms not amenable to reconstruction with a single-stent due to anatomical conformation $(40,41)$. Y- and X-stent reconstructions enable the endovascular management of otherwise complex, wide-neck 
cerebral aneurysms and can be performed as safely as single-stent technique in experienced hands with satisfactory results.

\section{Y-stent and waffle-cone technique}

The Y-stent technique has been developed first to treat wide-neck basilar tip aneurysms (42). It includes the crossing-Y and kissing$\mathrm{Y}$ techniques (43). The crossing Y-stent technique is based on the strategy that a second stent is advanced through the first stent interstices and into the contralateral branch vessel. By contrast the kissing technique, two stents are deployed in a parallel fashion from both daughter arterial branches down to the main arterial trunk, forming a kissing-Y configuration. The first bifurcation vessel to be stented is determined according to the angle between the proximal parent vessel and the arterial branches just distal to the aneurysm; the branch with a sharper angle to be stented before the one with wider angle. In 2004, Horowitz et al. described a single-stent technique to treat broad-neck bifurcation aneurysm consisting in a single-stent to be placed partially into the aneurysm and into the afferent artery, the portion of the stent protruding into the aneurysm fundus providing neck support for the subsequent successful coiling (44).

\section{X-stent technique}

Anterior communicating artery (AcoA) aneurysms may present with complex anatomic features, often associated with a wide-neck and variety of anomalies. X-configured stent-assisted coiling for treatment of wide-neck and complex AcoA aneurysms, for which otherwise there would be no endovascular treatment alternative $(40,45)$. Of course, X-stent placement is to be reserved for patients having good-sized A1 segments, bilaterally. The side of the first stent is determined according to the angle between the A1-AcoA complex and the contralateral A2; the A2 with a sharper angle to be stented before the one with wider angle. On the basis of this decision, the first stent is placed across the aneurysm neck, extending from the contralateral $\mathrm{A} 2$ to the ipsilateral $\mathrm{A} 1$ segment, crossing through the AcoA. Then after, the second stent is crossed from the other side. Both strut crossing and kissing stenting technique have been reported $(40,45-47)$.

\section{EFFECT OF SACT ON IMMEDIATE ANGIOGRAPHIC OUTCOME AND AT FOLLOW-UP}

Immediate angiographic complete occlusions are obtained less frequently in stented than in the not stented aneurysms. This is because larger aneurysms are more likely to be stented than small aneurysms, and that dual antiplatelet therapy impacts on the immediate intra-aneurysmal thrombosis. Moreover, the use of dual antiplatelet therapy during the procedure in addition to heparin does not favor immediate per procedural sac thrombosis (25). Tight coiling is more difficult to obtain when the stent is implanted prior to coiling, giving less maneuverability to the coiling microcatheter thus resulting in looser aneurysm packing.

Conversely, at follow-up, complete occlusions increased to $73.4 \%$ in the stent-assisted group, while it diminished to $54.0 \%$ in the no-stent group. For stent-assisted coiling, numerous articles have reported a broad range (13.2-94.4\%) of immediate complete occlusion (48-54). However, most mid-to-long-term follow-up series have reported augmented rates of angiographic complete occlusion at follow-up (range 54-81\%) (24-26, 49-62). An absence of stent has been identified as one of the most relevant factors for angiographic recurrence (25). This durability can be explained by the combination of biological, geometrical, and hemodynamic mechanisms (63-68). Hemodynamic effects of the stents in the endovascular treatment of aneurysms include disruption of intra-aneurysmal flow pattern, resulting in turbulence, and production of blood stasis within the aneurysm, resulting in aneurysmal thrombosis. This hemodynamic effect seems even more preeminent in case of Y-stenting (65).

\section{COMPLICATIONS OF SACT}

There are more procedure-related complications than in the standalone coiling. The main cause of morbidity and mortality is thromboembolism. The necessity of dual antiplatelet therapy in SACT is also known to increase the risk of hemorrhagic complications (69). Thromboembolic complications are also more frequent in the stented patients (70). Antiplatelet activity assessment prior to stent delivery allows diminishing the occurrence of such complications by identifying the patients not responding to antiplatelet drugs $(71,72)$. In a recent review article, Shapiro et al. reported an overall complication incidence of $19 \%$, with an overall death incidence of $2.1 \%$. Thromboembolic issues were most prevalent at close to $10 \%$, leading to death in $0.6 \%$ of overall cases. Hemorrhagic complications occurred in $2.2 \%$ of cases but carried a higher association with mortality, accounting for $0.9 \%$ of overall deaths. Coil-related technical issues were infrequent (2\%) and almost always asymptomatic. Complication rates decrease overtime while the operator practice of stenting increased showing also the effect of a learning curve (26). More recently, Nishido et al. have reported $7.0 \%$ of ischemic and $2.3 \%$ of hemorrhagic complications with an overall rate of procedure-induced mortality of $2.7 \%$ with SACT (73). Geyik et al., in a series of 500 consecutive SACT aneurysms, reported $5.6 \%$ of thromboembolic and $0.8 \%$ of hemorrhagic complications, with a procedure-related mortality of $0.8 \%$ (74). Table 2 provides with an overview of the rates of complications with SACT.

\section{SACT IN THE ACUTE SETTING OF SAH}

The use of SACT in the acute setting of subarachnoid hemorrhage remains controversial despite positive results reported in limited series $(75,76)$. It appears that the risks of intracranial hemorrhage are augmented in this particular condition. In their review article, Bodily et al. reported that SACT in ruptured aneurysms

Table 2 | Stent-assisted coiling technique complications with clinical significance.

\begin{tabular}{lcc}
\hline & \multicolumn{2}{c}{ Morbi-mortality } \\
\cline { 2 - 3 } & $\begin{array}{l}\text { Stand-alone } \\
\text { coiling and BRT }\end{array}$ & SACT \\
\hline $\begin{array}{l}\text { Nishido et al. (73) unruptured and } \\
\text { ruptured aneurysms }\end{array}$ & $5.6 \%$ & $9.4 \%$ \\
$\begin{array}{l}\text { Shapiro et al. (10) review, unruptured } \\
\text { and ruptured aneurysms }\end{array}$ & NA & $12.2 \%$ \\
\end{tabular}


could be performed with high degrees of technical success, but adverse events appeared more common and clinical outcomes were likely worse than those achieved without stent assistance (30). The optimal antiplatelet medication during acute-phase treatment has yet to be determined, and a longer follow-up series is needed to evaluate the long-term efficacy and safety of stent-assisted coil embolization during acute SAH. In a series of 36 patients, Golshani et al. found that SACT was an option for treatment of ruptured wide-neck ruptured aneurysms and for salvage treatment during unassisted embolization of ruptured aneurysms but complication rates appeared to be higher than for routine clipping or coiling of cerebral aneurysms (28). This applies even more dramatically to the patients requiring ventriculostomy (77).

\section{WHEN TO USE BAT}

In our center, BAT is used in slightly over $60 \%$ of the cases for both ruptured and unruptured aneurysms. BAT provides the ability to avoid coil protrusion and to protect from the deleterious effect of a massive subarachnoid hemorrhage in case of aneurysm perforation. The balloon can be immediately inflated in case of dome (re)rupture during intervention. The main drawback of the technique is the need for dual femoral approach, augmenting the potential for access site complications. Alternatively some operators advocate the use of a single guiding catheter (with a minimal inner lumen diameter of $0.070^{\prime \prime}$ ), allowing the navigation of both the balloon and the coil delivery microcatheters. The main drawback of this single guiding catheter technique is the potential inadvertent forward and backward movements of one of the two microcatheters while manipulating the second one.

\section{WHEN TO USE SACT}

The need for dual antiplatelet therapy makes the SACT to be avoided in acutely ruptured aneurysms. In this setting, SACT should be reserved as a bail-out procedure to avoid parent vessel closure when inadvertent coil protrusion is threatening. We rather prefer to perform a partial coiling to protect the fundus of the aneurysm to avoid early rebleed and to carry back the patient to the angiographic suite a few weeks later to optimize the aneurysm occlusion with the adjunct of a stent if required.

\section{ANTIPLATELET THERAPY MANAGEMENT FOR ELECTIVE SACT}

Our standard dual antiplatelet regimen is based on the oral administration of clopidogrel and aspirin. Instead of using a loading dose of clopidogrel we initiate dual antiplatelet therapy (clopidogrel and oral aspirin) 10-15 days prior to the procedure. For antiplatelet activity assessment we use the VerifyNow (Accumetrics, San Diego,

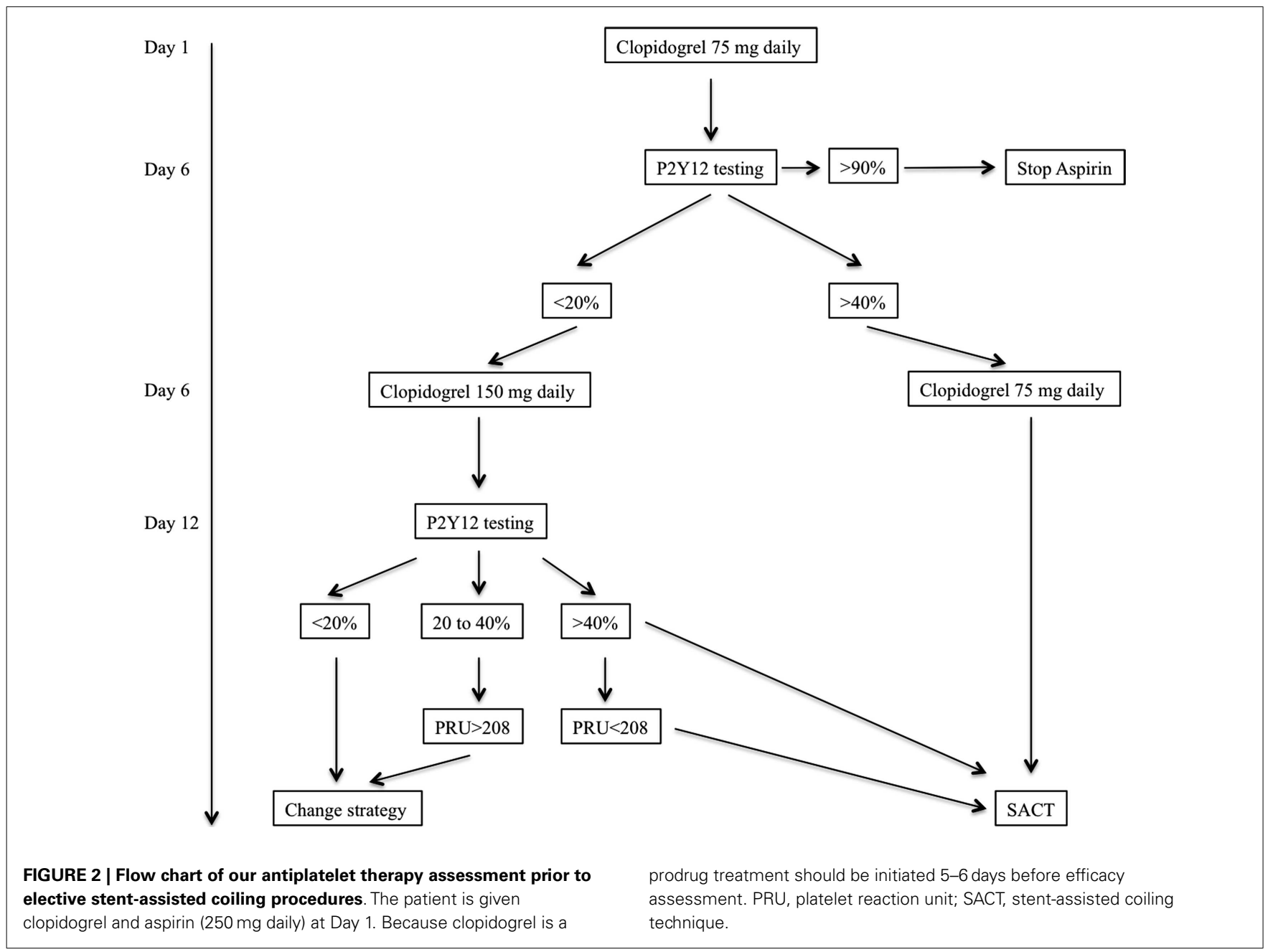


CA, USA) system which a bedside system that is requiring minimal manipulation. This measurement is based on the principles of optical aggregometry. Because low responder patients may not be recognized with loading dose we rather prefer to initiate the treatment with a standard dose of Clopidogrel (75-150 mg daily). Our protocol has been standardized and applied to all patients for whom elective aneurysm treatment with SACT is scheduled (Figure 2).

\section{CONCLUSION}

Despite the fact that aneurysms treated by the remodeling technique are different from aneurysms treated with standard coiling, the safety of both techniques is similar with a higher anatomic efficacy of the remodeling technique. Accordingly, wide use of the remodeling technique can be proposed. SACT is associated with a higher mortality compared with coiling with or without remodeling and remains more hazardous than stand-alone or BRT coiling in keeping with augmented risks of both ischemic and hemorrhagic insults. However, SACT reduce significantly angiographic recurrence, a factor that alters the results of endovascular treatment over surgical clipping. In the setting of subarachnoid hemorrhage, SACT should be reserved to the otherwise untreatable aneurysm, even if BRT is used, in order to protect the patient from early rebleeding. The optimal antiplatelet regimen in the acute setting has not been determined yet.

\section{REFERENCES}

1. Moret J, Cognard C, Weill A, Castaings L, Rey A. The "remodelling technique" in the treatment of wide neck intracranial aneurysms. Angiographic results and clinical follow-up in 56 cases. Interv Neuroradiol (1997) 3:21-35.

2. Spiotta AM, Miranpuri A, Chaudry MI, Turner RD IV, Turk AS. Combined balloon stent technique with the scepter $\mathrm{C}$ balloon and low-profile visualized intraluminal stent for the treatment of intracranial aneurysms. J Neurointerv Surg (2013) 5(Suppl 3):iii79-82. doi:10.1136/neurintsurg-2012-010553

3. Baldi S, Mounayer C, Piotin M, Spelle L, Moret J. Balloon-assisted coil placement in wide-neck bifurcation aneurysms by use of a new, compliant balloon microcatheter. AJNR Am J Neuroradiol (2003) 24:1222-5.

4. Arat A, Cil B. Double-balloon remodeling of wide-necked aneurysms distal to the circle of Willis. AJNR Am J Neuroradiol (2005) 26:1768-71.

5. Moret J, Ross IB, Weill A, Piotin M. The retrograde approach: a consideration for the endovascular treatment of aneurysms. AJNR Am J Neuroradiol (2000) 21:262-8.

6. Clarençon F, Pérot G, Biondi A, Di Maria F, Szatmary Z, Chiras J, et al. Use of the ascent balloon for a 2-in-1 remodeling technique: feasibility and initial experience: case report. Neurosurgery (2012) 70:170-3. doi:10.1227/NEU. 0b013e31822c49ad

7. Pierot L, Cognard C, Anxionnat R, Ricolfi F; CLARITY Investigators. Remodeling technique for endovascular treatment of ruptured intracranial aneurysms had a higher rate of adequate postoperative occlusion than did conventional coil embolization with comparable safety. Radiology (2011) 258:546-53. doi:10.1148/radiol.10100894

8. Pierot L, Spelle L, Leclerc X, Cognard C, Bonafé A, Moret J. Endovascular treatment of unruptured intracranial aneurysms: comparison of safety of remodeling technique and standard treatment with coils. Radiology (2009) 251:846-55. doi:10.1148/radiol.2513081056

9. Shapiro M, Babb J, Becske T, Nelson PK. Safety and efficacy of adjunctive balloon remodeling during endovascular treatment of intracranial aneurysms: a literature review. AJNR Am J Neuroradiol (2008) 29:1777-81. doi:10.3174/ajnr.A1216

10. Sluzewski M, van Rooij WJ, Beute GN, Nijssen PC. Balloon-assisted coil embolization of intracranial aneurysms: incidence, complications, and angiography results. J Neurosurg (2006) 105:396-9. doi:10.3171/jns.2006.105.3.396

11. Layton KF, Cloft HJ, Gray LA, Lewis DA, Kallmes DF. Balloon-assisted coiling of intracranial aneurysms: evaluation of local thrombus formation and symptomatic thromboembolic complications. AJNR Am J Neuroradiol (2007) 28:1172-5. doi:10.3174/ajnr.A0490

12. Brooks NP, Turk AS, Niemann DB, Aagaard-Kienitz B, Pulfer K, Cook T. Frequency of thromboembolic events associated with endovascular aneurysm treatment: retrospective case series. J Neurosurg (2008) 108:1095-100. doi:10.3171/ JNS/2008/108/6/1095

13. Albayram S, Selcuk H, Kara B, Bozdag E, Uzma O, Kocer N, et al. Thromboembolic events associated with balloon-assisted coil embolization: evaluation with diffusion-weighted MR imaging. AJNR Am J Neuroradiol (2004) 25:1768-77.

14. Spiotta AM, Bhalla T, Hussain MS, Sivapatham T, Batra A, Hui F, et al. An analysis of inflation times during balloon-assisted aneurysm coil embolization and ischemic complications. Stroke (2011) 42:1051-5. doi:10.1161/STROKEAHA. 110.602276

15. Johnston SC, Dowd CF, Higashida RT, Lawton MT, Duckwiler GR, Gress DR, et al. Predictors of rehemorrhage after treatment of ruptured intracranial aneurysms: the cerebral aneurysm rerupture after treatment (CARAT) study. Stroke (2008) 39:120-5. doi:10.1161/STROKEAHA.107.495747

16. Raymond J, Guilbert F, Weill A, Georganos SA, Juravsky L, Lambert A, et al. Long-term angiographic recurrences after selective endovascular treatment of aneurysms with detachable coils. Stroke (2003) 34:1398-403. doi:10.1161/01. STR.0000073841.88563.E9

17. Henkes H, Bose A, Felber S, Miloslavski E, Berg-Dammer E, Kühne D. Endovascular coil occlusion of intracranial aneurysms assisted by a novel self-expandable nitinol microstent (neuroform). Interv Neuroradiol (2002) 8:107-19.

18. Higashida RT, Halbach VV, Dowd CF, Juravsky L, Meagher S. Initial clinical experience with a new self-expanding nitinol stent for the treatment of intracranial cerebral aneurysms: the cordis enterprise stent. AJNR Am J Neuroradiol (2005) 26:1751-6.

19. Cekirge HS, Yavuz K, Geyik S, Saatci I. A novel "Y" stent flow diversion technique for the endovascular treatment of bifurcation aneurysms without endosaccular coiling. AJNR Am J Neuroradiol (2011) 32:1262-8. doi:10.3174/ajnr.A2475

20. Ediriwickrema A, Williamson T, Hebert R, Matouk C, Johnson MH, Bulsara KR. Intracranial stenting as monotherapy in subarachnoid hemorrhage and sickle cell disease. J Neurointerv Surg (2013) 5:e4. doi:10.1136/neurintsurg2011-010224

21. Pumar JM, Lete I, Pardo MI, Vázquez-Herrero F, Blanco M. LEO stent monotherapy for the endovascular reconstruction of fusiform aneurysms of the middle cerebral artery. AJNR Am J Neuroradiol (2008) 29:1775-6. doi:10.3174/ajnr. A1155

22. Takemoto K, Tateshima S, Rastogi S, Gonzalez N, Jahan R, Duckwiler G, et al. Disappearance of a small intracranial aneurysm as a result of vessel straightening and in-stent stenosis following use of an enterprise vascular reconstruction device. J Neurointerv Surg (2014) 6(1):e4. doi:10.1136/neurintsurg-2012010583.rep

23. Teng MM, Luo CB, Chang FC, Harsan H. Treatment of intracranial aneurysm with bare stent only. Interv Neuroradiol (2008) 14(Suppl 2):75-8.

24. Lawson MF, Newman WC, Chi YY, Mocco JD, Hoh BL. Stent-associated flow remodeling causes further occlusion of incompletely coiled aneurysms. Neurosurgery (2011) 69:598-603. doi:10.1227/NEU.0b013e3182181c2b

25. Piotin M, Blanc R, Spelle L, Mounayer C, Piantino R, Schmidt PJ, et al. Stentassisted coiling of intracranial aneurysms: clinical and angiographic results in 216 consecutive aneurysms. Stroke (2010) 41:110-5. doi:10.1161/STROKEAHA. 109.558114

26. Shapiro M, Becske T, Sahlein D, Babb J, Nelson PK. Stent-supported aneurysm coiling: a literature survey of treatment and follow-up. AJNR Am J Neuroradiol (2012) 33:159-63. doi:10.3174/ajnr.A2719

27. Turk AS, Niemann DB, Ahmed A, Aagaard-Kienitz B. Use of self-expanding stents in distal small cerebral vessels. AJNR Am J Neuroradiol (2007) 28:533-6.

28. Golshani K, Ferrel A, Lessne M, Shah P, Chowdhary A, Choulakian A, et al. Stentassisted coil emboilization of ruptured intracranial aneurysms: a retrospective multicenter review. Surg Neurol Int (2012) 3:84. doi:10.4103/2152-7806.99174

29. McDonald JS, Norgan AP, McDonald RJ, Lanzino G, Kallmes DF, Cloft HJ. In-hospital outcomes associated with stent-assisted endovascular treatment of unruptured cerebral aneurysms in the USA. J Neurointerv Surg (2012) 5(4):317-20. doi:10.1136/neurintsurg-2012-010349

30. Bodily KD, Cloft HJ, Lanzino G, Fiorella DJ, White PM, Kallmes DF. Stentassisted coiling in acutely ruptured intracranial aneurysms: a qualitative, systematic review of the literature. AJNR Am J Neuroradiol (2011) 32:1232-6. doi:10.3174/ajnr.A2478 
31. Lee DH, Arat A, Morsi H, Diaz O, Jou LD, Mawad ME. Intimal thickening after placement of a neuroform stent. Its incidence and relation to angiographic follow-up results of aneurysm embolization. Interv Neuroradiol (2007) 13:239-46.

32. Riedel CH, Tietke M, Alfke K, Stingele R, Jansen O. Subacute stent thrombosis in intracranial stenting. Stroke (2009) 40:1310-4. doi:10.1161/STROKEAHA.108. 531400

33. Chalouhi N, Drueding R, Starke RM, Jabbour P, Dumont AS, Gonzalez LF, et al. In-stent stenosis after stent-assisted coiling: incidence, predictors and clinical outcomes of 435 cases. Neurosurgery (2013) 72:390-6. doi:10.1227/NEU. 0b013e31828046a6

34. De Bock S, Iannaccone F, De Santis G, De Beule M, Mortier P, Verhegghe B, et al. Our capricious vessels: the influence of stent design and vessel geometry on the mechanics of intracranial aneurysm stent deployment. J Biomech (2012) 45:1353-9. doi:10.1016/j.jbiomech.2012.03.012

35. Ebrahimi N, Claus B, Lee CY, Biondi A, Benndorf G. Stent conformity in curved vascular models with simulated aneurysm necks using flat-panel CT: an in vitro study. AJNR Am J Neuroradiol (2007) 28:823-9.

36. Heller RS, Miele WR, Do-Dai DD, Malek AM. Crescent sign on magnetic resonance angiography revealing incomplete stent apposition: correlation with diffusion-weighted changes in stent-mediated coil embolization of aneurysms. J Neurosurg (2011) 115:624-32. doi:10.3171/2011.4.JNS102050

37. Benitez RP, Silva MT, Klem J, Veznedaroglu E, Rosenwasser RH. Endovascular occlusion of wide-necked aneurysms with a new intracranial microstent (neuroform) and detachable coils. Neurosurgery (2004) 54:1359-67. doi:10.1227/01. NEU.0000124484.87635.CD

38. Broadbent LP, Moran CJ, Cross DT III, Derdeyn CP. Management of neuroform stent dislodgement and misplacement. AJNR Am J Neuroradiol (2003) 24:1819-22.

39. de Paula Lucas C, Piotin M, Spelle L, Moret J. Stent-jack technique in stentassisted coiling of wide-neck aneurysms. Neurosurgery (2008) 62:ONS414-6. doi:10.1227/01.neu.0000326028.47090.5f

40. Saatci I, Geyik S, Yavuz K, Cekirge S. X-configured stent-assisted coiling in the endovascular treatment of complex anterior communicating artery aneurysms: a novel reconstructive technique. AJNR Am J Neuroradiol (2011) 32:E113-7. doi:10.3174/ajnr.A2111

41. Spiotta AM, Gupta R, Fiorella D, Gonugunta V, Lobo B, Rasmussen PA, et al. Mid-term results of endovascular coiling of wide-necked aneurysms using double stents in a Y configuration. Neurosurgery (2011) 69:421-9. doi:10.1227/NEU. 0b013e318214abbd

42. Chow MM, Woo HH, Masaryk TJ, Rasmussen PA. A novel endovascular treatment of a wide-necked basilar apex aneurysm by using a Y-configuration, double-stent technique. AJNR Am J Neuroradiol (2004) 25:509-12.

43. Zhao KJ, Yang PF, Huang QH, Li Q, Zhao WY, Liu JM, et al. Y-configuration stent placement (crossing and kissing) for endovascular treatment of wide-neck cerebral aneurysms located at 4 different bifurcation sites. AJNR Am J Neuroradiol (2012) 33:1310-6. doi:10.3174/ajnr.A2961

44. Horowitz M, Levy E, Sauvageau E, Genevro J, Guterman LR, Hanel R, et al. Intra/extra-aneurysmal stent placement for management of complex and wide-necked- bifurcation aneurysms: eight cases using the waffle cone technique. Neurosurgery (2006) 58:ONS258-62. doi:10.1227/01.NEU.0000204713. 24945.D2

45. Lazzaro MA, Zaidat OO. X-configuration intersecting enterprise stents for vascular remodeling and assisted coil embolization of a wide neck anterior communicating artery aneurysm. J Neurointerv Surg (2011) 3:348-51. doi:10.1136/jnis.2011.004796

46. Zelenák K, Zelenáková J, DeRiggo J, Kurca E, Boudný J, Polácek H. Flow changes after endovascular treatment of a wide-neck anterior communicating artery aneurysm by using X-configured kissing stents (cross-kissing stents) technique. Cardiovasc Intervent Radiol (2011) 34:1308-11. doi:10.1007/s00270011-0153-7

47. Yavuz K, Geyik S, Cekirge S, Saatci I. Double stent-assisted coil embolization treatment for bifurcation aneurysms: immediate treatment results and long-term angiographic outcome. AJNR Am J Neuroradiol (2013) 34:1778-84. doi:10.3174/ajnr.A3464

48. Akpek S, Arat A, Morsi H, Klucznick RP, Strother CM, Mawad ME. Selfexpandable stent-assisted coiling of wide-necked intracranial aneurysms: a single-center experience. AJNR Am J Neuroradiol (2005) 26:1223-31.
49. Biondi A, Janardhan V, Katz JM, Salvaggio K, Riina HA, Gobin YP. Neuroform stent-assisted coil embolization of wide-neck intracranial aneurysms: strategies in stent deployment and midterm follow-up. Neurosurgery (2007) 61:460-8. doi:10.1227/01.NEU.0000290890.62201.A9

50. Fargen KM, Hoh BL, Welch BG, Pride GL, Lanzino G, Boulos AS, et al. Long-term results of enterprise stent-assisted coiling of cerebral aneurysms. Neurosurgery (2012) 71:239-44. doi:10.1227/NEU.0b013e3182571953

51. Bandeira A, Raphaeli G, Balériaux D, Bruneau M, De Witte O, Lubicz B. Selective embolization of unruptured intracranial aneurysms is associated with low retreatment rate. Neuroradiology (2010) 52:141-6. doi:10.1007/s00234-0090607-7

52. Maldonado IL, Machi P, Costalat V, Mura T, Bonafé A. Neuroform stent-assisted coiling of unruptured intracranial aneurysms: short- and midterm results from a single-center experience with 68 patients. AJNR Am J Neuroradiol (2011) 32:131-6. doi:10.3174/ajnr.A2245

53. Mocco J, Fargen KM, Albuquerque FC, Bendok BR, Boulos AS, Carpenter JS, et al. Delayed thrombosis or stenosis following enterprise-assisted stent-coiling: is it safe? Midterm results of the interstate collaboration of enterprise stent coiling. Neurosurgery (2011) 69:908-13. doi:10.1227/NEU.0b013e318228490c

54. Yahia AM, Latorre JG, Gordon V, Whapham J, Swarnkar A, Fessler RD. Progressive occlusion of aneurysms in neuroform stent-assisted treatment of intracranial aneurysms. J Neurol Neurosurg Psychiatry (2011) 82:278-82. doi:10.1136/ jnnp.2009.173864

55. Hwang G, Park H, Bang JS, Jin SC, Kim BC, Oh CW, et al. Comparison of 2year angiographic outcomes of stent- and nonstent-assisted coil embolization in unruptured aneurysms with an unfavorable configuration for coiling. AJNR Am J Neuroradiol (2011) 32:1707-10. doi:10.3174/ajnr.A2592

56. Izar B, Rai A, Raghuram K, Rotruck J, Carpenter J. Comparison of devices used for stent-assisted coiling of intracranial aneurysms. PLoS One (2011) 6:e24875. doi:10.1371/journal.pone.0024875

57. Santillan A, Greenberg E, Patsalides A, Salvaggio K, Riina HA, Gobin YP. Longterm clinical and angiographic results of neuroform stent-assisted coil embolization in wide-necked intracranial aneurysms. Neurosurgery (2012) 70:1232-7. doi:10.1227/NEU.0b013e3182422a68

58. Clajus C, Sychra V, Strasilla C, Klisch J. Stent-assisted coil embolization of intracranial aneurysms using the solitaire $\mathrm{AB}$ neurovascular remodeling device: initial and midterm follow-up results. Neuroradiology (2013) 55(5):629-38. doi:10.1007/s00234-013-1148-7

59. Gu DQ, Zhang X, Luo B, Long XA, Duan CZ. The effect of neuroform stentassisted coil embolization of wide-necked intracranial aneurysms and clinical factors on progressive aneurysm occlusion on angiographic follow-up. J Clin Neurosci (2013) 20:244-7. doi:10.1016/j.jocn.2012.01.053

60. Jahshan S, Abla AA, Natarajan SK, Drummond PS, Kan P, Karmon Y, et al. Results of stent-assisted vs non-stent-assisted endovascular therapies in 489 cerebral aneurysms: single-center experience. Neurosurgery (2013) 72:232-9. doi:10.1227/NEU.0b013e31827b93ea

61. Johnson AK, Heiferman DM, Lopes DK. Stent-assisted embolization of 100 middle cerebral artery aneurysms. J Neurosurg (2013) 118(5):950-5. doi:10.3171/ 2013.1.JNS121298

62. Kulcsár Z, Göricke SL, Gizewski ER, Schlamann M, Sure U, Sandalcioglu IE, et al. Neuroform stent-assisted treatment of intracranial aneurysms: long-term follow-up study of aneurysm recurrence and in-stent stenosis rates. Neuroradiology (2013) 55(4):459-65. doi:10.1007/s00234-013-1143-z

63. Ohta M, Hirabayashi M, Wetzel S, Lylyk P, Wata H, Tsutsumi S, et al. Impact of stent design on intra-aneurysmal flow. A computer simulation study. Interv Neuroradiol (2004) 10(Suppl 2):85-94.

64. Sani S, Lopes DK. Treatment of a middle cerebral artery bifurcation aneurysm using a double neuroform stent "Y" configuration and coil embolization: technical case report. Neurosurgery (2005) 57:E209. doi:10.1227/01.NEU.0000163684. 75204.CD

65. Gao B, Baharoglu MI, Cohen AD, Malek AM. Y-stent coiling of basilar bifurcation aneurysms induces a dynamic angular vascular remodeling with alteration of the apical wall shear stress pattern. Neurosurgery (2012) 72(4):617-29. doi:10.1227/NEU.0b013e3182846d9f

66. Gao B, Baharoglu MI, Cohen AD, Malek AM. Stent-assisted coiling of intracranial bifurcation aneurysms leads to immediate and delayed intracranial vascular angle remodeling. AJNR Am J Neuroradiol (2012) 33:649-54. doi:10.3174/ajnr. A2841 
67. Huang QH, Wu YF, Xu Y, Hong B, Zhang L, Liu JM. Vascular geometry change because of endovascular stent placement for anterior communicating artery aneurysms. AJNR Am J Neuroradiol (2011) 32:1721-5. doi:10.3174/ajnr. A2597

68. Gao B, Baharoglu MI, Malek AM. Angular remodeling in single stent-assisted coiling displaces and attenuates the flow impingement zone at the neck of intracranial bifurcation aneurysms. Neurosurgery (2013) 72(5):739-48. doi:10. 1227/NEU.0b013e318286fab3

69. Tumialán LM, Zhang YJ, Cawley CM, Dion JE, Tong FC, Barrow DL. Intracranial hemorrhage associated with stent-assisted coil embolization of cerebral aneurysms: a cautionary report. J Neurosurg (2008) 108:1122-9. doi:10.3171/ JNS/2008/108/6/1122

70. Yahia AM, Gordon V, Whapham J, Malek A, Steel J, Fessler RD. Complications of neuroform stent in endovascular treatment of intracranial aneurysms. Neurocrit Care (2008) 8:19-30. doi:10.1007/s12028-007-9001-7

71. Müller-Schunk S, Linn J, Peters N, Spannagl M, Deisenberg M, Brückmann H, et al. Monitoring of clopidogrel-related platelet inhibition: correlation of nonresponse with clinical outcome in supra-aortic stenting. AJNR Am J Neuroradiol (2008) 29:786-91. doi:10.3174/ajnr.A0917

72. Pandya DJ, Fitzsimmons BF, Wolfe TJ, Hussain SI, Lynch JR, Ortega-Gutierrez S, et al. Measurement of antiplatelet inhibition during neurointerventional procedures: the effect of antithrombotic duration and loading dose. J Neuroimaging (2010) 20:64-9. doi:10.1111/j.1552-6569.2008.00322.x

73. Nishido H, Piotin M, Bartolini B, Pistocchi S, Redjem H, Blanc R. Analysis of complications and recurrences of aneurysm coiling with special emphasis on the stent-assisted technique. AJNR Am J Neuroradiol (2014) 35:339-44. doi:10.3174/ajnr.A3658

74. Geyik S, Yavuz K, Yurttutan N, Saatci I, Cekirge HS. Stent-assisted coiling in endovascular treatment of 500 consecutive cerebral aneurysms with long-term follow-up. AJNR Am J Neuroradiol (2013) 34(11):2157-62. doi:10.3174/ajnr. A3574
75. Katsaridis V, Papagiannaki C, Violaris C. Embolization of acutely ruptured and unruptured wide-necked cerebral aneurysms using the neuroform 2 stent without pretreatment with antiplatelets: a single center experience. AJNR Am J Neuroradiol (2006) 27:1123-8.

76. Tähtinen OI, Vanninen RL, Manninen HI, Rautio R, Haapanen A, Niskakangas T, et al. Wide-necked intracranial aneurysms: treatment with stent-assisted coil embolization during acute ( $<72$ hours) subarachnoid hemorrhage - experience in 61 consecutive patients. Radiology (2009) 253:199-208. doi:10.1148/radiol. 2531081923

77. Kung DK, Policeni BA, Capuano AW, Rossen JD, Jabbour PM, Torner JC, et al. Risk of ventriculostomy-related hemorrhage in patients with acutely ruptured aneurysms treated using stent-assisted coiling. J Neurosurg (2011) 114:1021-7. doi:10.3171/2010.9.JNS10445

Conflict of Interest Statement: The authors declare that the research was conducted in the absence of any commercial or financial relationships that could be construed as a potential conflict of interest.

Received: 27 December 2013; accepted: 19 March 2014; published online: 08 April 2014. Citation: Piotin M and Blanc R (2014) Balloons and stents in the endovascular treatment of cerebral aneurysms: vascular anatomy remodeled. Front. Neurol. 5:41. doi: 10.3389/fneur.2014.00041

This article was submitted to Endovascular and Interventional Neurology, a section of the journal Frontiers in Neurology.

Copyright $(2014$ Piotin and Blanc. This is an open-access article distributed under the terms of the Creative Commons Attribution License (CC BY). The use, distribution or reproduction in other forums is permitted, provided the original author(s) or licensor are credited and that the original publication in this journal is cited, in accordance with accepted academic practice. No use, distribution or reproduction is permitted which does not comply with these terms. 